\title{
Resilience in post-socialist context: The case of a watermelon producing community in Hungary
}

\author{
Márton Lendvay ${ }^{1}$
}

\begin{abstract}
The aim of this paper is to test whether the concept of resilience can be applied to rural communities in postsocialist transition countries such as Hungary. Resilience, a concept engaged with the dynamics of change, has gained popularity in recent years following the post- 2008 crisis and has become a core theme of academic, policy and lay discourses in the Anglo-Saxon world. The ongoing processes of socio-economic transition within the post-socialist environment have also attracted wide attention in the past decades, although not within the frameworks of resilience thinking. The concept of resilience is missing from post-socialist discourses and has not been applied to rural communities before in an Eastern European context, although the nature of post-socialist transition characterised by complexity, cross-scalar processes and multiplicity of actors involved make it an especially suitable field for resilience studies. In this paper, we aim to flag the potential directions and successful application of the concept of resilience both as a research topic and as a tool for researchers of the post-socialist space while we caution for the potential pitfalls and misuses of the concept and critically analyse aspects that attracted wide debates. We illustrate how rural community resilience may be conceptualised on the example of the watermelon producing community of Medgyesegyháza, Hungary.
\end{abstract}

Keywords: resilience, rural community, neo-liberalism, post-socialism, actor-network theory, assemblage, non-human agency

\section{Introduction}

The concept of resilience thinking - as understanding a system's capacity to absorb disturbances and adversity so as to maintain its original level of functioning - emerged in the field of rural geography, regional planning and popular discourses during the new millennium. The notion of resilience arose as a response to crises. Crises have always hit rural regions and the post-2008 crisis is just one of a series of socio-economic disruptions affecting places, spaces, and systems. This crisis, however, happened simultaneously with the emergence of other environmental risks, forming the coupling of "a deep economic crisis with a perceived threat of an imminent ecological crisis, above all because of climate change" (Hudson, R. 2010, 12). This intersection of somewhat traditional scientific and policy research interests culminated in the emergence of the new research agenda, resilience, embracing research on economic instability, environmental sensitivity and other potentially profound domains of transition (Sсотт, M. 2013). Beyond applications of resilience focusing on urban regions, ecosystems etc. 'rural' resilience is especially useful because it directly links peoples, economies and the natural environment they rely on, live on and make their living off. This wide applicability and its growing popularity made rural community resilience a catchword.

One may even pose the question what the added value of introducing a new concept could be, if, at all it would have a different meaning from vulnerability, stability and especially sustainability. The recent success of the notion of resilience is beyond doubt due to the emergence of a 'post-sustainability'

\footnotetext{
${ }^{1}$ Department of Geography and Earth Sciences, Aberystwyth University, Aberystwyth, Ceredigion, United Kingdom SY23 3DB. E-mail: mal59@aber.ac.uk
} 
discourse admitting that the ideal of sustainability - as reaching eternity by a once in a lifetime fine-tuning of systems - has failed and shocks and stresses we cannot prepare for will always occur. Conceptualising the difference between sustainability and resilience is not an easy task (Ludwig, D. et al. 1997) and has not attracted sufficient attention until now. In his works on the dynamics of sustainability STIRLING, A. (2014) regards durability, stability, resilience and robustness - as dependents of temporality of change and potency of action - as necessary but individually insufficient dynamic properties of sustainability; in his formulation resilience is a component of sustainability.

Although thinking about rural change and persistence has a wide heritage and long history in fields such as community development (Adger, W.N. 2000), community health (Almedom, A. 2005) and studies of resource dependency and sustainability (MARSDEN, T.K. 2003; SMith, E. and MARsDEN, T.K. 2004), the more explicit focus on 'rural community resilience' feeds from two markedly different strands of inquiry. Being situated on the crossroads of various approaches, the complex concept created a hybrid of ecology and psychology (Lendvay, M. 2013a).

At the same time, another traditional strand of works has been interested in postsocialist transition; a process that has been characterised by processes of change and persistence on multiple scales in the former socialist states in the past quarter-century. More than 25 years after the regime shift the notion of post-socialism is not a completed process of change, but an ongoing transformation that includes:

- a mixture of the images of a pre-socialist era,

- legacies and memories of (imagined) socialist past (KAY, R. et al. 2012),

- the results and images of a transition process from the collapse of socialism through the period of democratisation and privatisation, the accession of the EU and the global economic crisis since 2008, together with joining a global competition,
- and the variability (Herrschel, T. 2007) of personal stories that determine how members of the communities view the above three (Lendvay, M. 2016).

In this paper, we argue that resilience is a concept that may help us understand why and how rural regions of the post-socialist space change the way they do, how certain legacies of the past remain dominant while mixing with new processes and result in multiplicity and a turbulent environment. The question we aim to answer in this article is: how can resilience thinking be applied to a rural post-socialist context? We are also interested in what the most promising avenues for applying the approach are and how we can avoid possible misuses.

This article discusses the potentials of resilience-thinking on the example of a watermelon producing community of Hungary. We start this paper by introducing the markedly different origins and definitions of the concept and indicate how these appear in the existing literature and introduce a theoretical framework we find the most useful approach in human geography. In the following sections, we indicate three fields of debate and also caution the readers to how resilience should not be treated. We then turn to the empirical analysis and discuss how resilience thinking could appear in a rural Hungarian context based on the theoretical foundations. The discussion synthesises the lessons of the empirical analysis and in the conclusions, we briefly summarise our findings.

\section{Theoretical foundations}

\section{Two traditions of resilience thinking}

Works on rural community resilience originally apply one of the two significantly different approaches: social-ecological-systems (SES) and community psychology. These two coexistent ways of thinking about change in rural regions have many implications on how community, change and resilience are viewed. Authors often claim the two 
approaches evolved simultaneously in the 1970s from the fields of ecology and child development psychology, therefore, those applying them either acknowledge HoLling, C.S. (1973) or GARMEZY, N. (1973) as founders of resilience thinking (CARPENTER, S.R. et al. 2001; Brown, D. and Kulig, J. 1996/97). Interestingly, deliberate attempts were made recently to integrate the two approaches (e.g. Berkes, F. and Ross, H. 2013).

SES approach is based on the idea that instead of focusing on only one subject, we should view a complex system that is built up of many interrelated components placed on different scales. This approach defines resilience as a measure of the amount of change a system can undergo and still retain the same controls on structure and function or remain in the same domain of attraction (CArpenter, S.R. et al. 2001). This definition implies that the system possesses multi-equilibria where a change in the configuration or stability of equilibria leads to the phenomenon of bifurcation (Ludwig, D. et al. 1997). According to the SES model modifications on a lower 'faster' scale can lead to changes in the functioning of a higher 'slower' scale, and thus transform the whole system - this is the basis of panarchy and the four-phase adaptive cycle metaphor (growth, equilibrium, collapse, and reorientation) that are key heuristics of this approach (GUNDERson, L.H. and Holling, C.S. 2002).

Economy-related studies such as those on resource dependent communities often apply this approach. In his reaction to common mistakes appearing in adaptive systems' analysis WALKER, B. $(2012,29)$ highlights:

- "A system cannot be understood or managed at one scale, they are inherently multiscale and their dynamics are dominated by cross-scale interactions.

- Attempt to make a system very resilient in one way, at one scale, can lead to it becoming less resilient in other ways at other scales.

- Resilience is not about not changing. Trying to keep a system in one particular state, or protecting it from disturbance in an effort to prevent change, lowers its resilience. (...)
- Resilience is neither good nor bad. There are many examples of very resilient undesirable system states (dictatorships, salinised landscapes). (...)"

The approach derived from community psychology (GARMEZY, N. 1973; KAPLAN, H.B. 1999) focuses much more on the adaptive capacities of individuals and groups, and their ability to recover after a disaster ('bounce-back' or 'return to normal' resilience) or to follow a single development pathway ('evolutionary' or 'bounce-forward' resilience) (Sсотт, M. 2013). As ExtercкотеR, R.K. et al. $(2015,117)$ put it very characteristically, most of such works look at how "different communities react and restructure themselves" when facing crises. To cope with stresses caused by social, political, and environmental change communities engage community resources in overcoming adversity and taking advantage of opportunities in response to change (e.g. Amundsen, $\mathrm{H}$. 2012; Buikstra, E. et al. 2010; Ross, H. et al. 2010). A very strong connection is assumed here between resilience and social capital (Cheshire, L. et al. 2015), the local power and capacity of communities to maintain their own futures. Amundsen, H. (2012) Buikstra, E. et al. (2010), Ross, H. et al. (2010) for example identifies community resources, community networks, institutions and services, peopleplace connections, active agents, and learning as dimensions activated in processes and activities in the course of a respond.

Using a similar approach, while discussing community resources MAGIS, K. (2010) highlights the role of community capital besides other forms of capital, natural or infrastructural capital for instance. She describes community capital as resources invested in community endeavours, defining it as "communities' ways of knowing the world, their values, and their assumptions about how things fit together. It is represented by symbols in language, art, and customs" (emphasis added) Magis, K. (2010, 406). Referring to FLORA, C. et al. (2004) MAGIs, K. (2010) adds it is this cultural capital that forms perceptions of life events and that is able to mobilise social rules and trigger power within a community. 
As visible, the different approaches to rural resilience tend to either focus on structures, materials and establishments or foreground to the agency of community members as individual actors. Recognising the shortcomings resulting from the gap between the two very different approaches recently there have been calls for the dissolution of this binary by applying a relational perspective focusing on interactions (Dwiartama, A. and Rosin, C. 2014, DARnhofer, I. et al. 2016). We argue here that resilience in human geography should dissolve the theoretical dichotomy and treat both large scale structures and agency of individuals on the common ontological framework. We suggest applying relational approaches such as Actor-Network Theory or assemblage theory.

\section{A relational approach}

One such relational approach is Actor-Network Theory (ANT) (LATOUR, B. 2005) that in this context draws on the idea of relationality, contingency and distributed agency of actors and the boundlessness and ephemerality of actor-networks with especial regards to how agricultural products constantly reproduce the rural network and at the same time modify its configuration (DwIARTAMA, A. and Rosin, C. 2014). Another approach, assemblage theory of Deleuze, G. and GuatTARI, F. (1987) - and its interpretation by DELANDA $(2002,2006)$ - is concerned with interacting parts and emergent wholes leading to flat ontologies that are "made exclusively of unique, singular individuals, differing in spatio-temporal scale but not in ontological status", according to DeLanda's definition (DeLanda, M. 2002, 47). Assemblages are built up of components that are defined by both physical and symbolic properties. As these components come together they establish new entities that are both materially assembled and symbolically coded with new, emergent properties.

Both ANT and assemblage theory allows us to consider structures and materials as having an agency, but the major difference is that actornetworks are extremely volatile, assemblages are more tightly set together. What is more, assemblage theory enables us to think through how communities are stabilised through the discourses and coding and meanings attached to certain components. Therefore, it not only concentrates on adaptability and new contingencies as ANT does, but thinks of more fixed entities that are still able to change in certain ways if the components are put together in new ways via 'lines of flights' Deleuze, G. and GuATtARI, F. (1987).

Relational approaches such as assemblage theory not only offer a theoretical but also an analytical framework to think about change. We find therefore assemblage theory an approach suitable to enable us to understand how communities - including people, non-human components, discourses, rules and regulations - come together and become a whole of interacting parts where functions of components are coded in one way or the other. This allows us to think through how people engage with each other, how they relate to large scale events, to the agricultural products and the land but assemblage theory also shows us how agricultural products trigger the performance of community actors for instance.

\section{Uses and misuses of the concept}

The different understandings and approaches to resilience generate three fields of debate that require special attention when putting the concept into practice. Unless we think through how we relate to these questions, we may easily apply the term resilience as a catchword.

\section{Awareness and intentionality}

Until now until now resilience was dealt with as a property that is visible, a process where we follow events, a concept that is revealed in some ways to community members, planners, researchers etc. Disaster readiness 
(NorRIs, F.H. et al. 2008), tackling anticipated disruptions (Adey, P. and Anderson, B. 2011), climate change mitigation but also the 'strengthening' of resilience, in general are all a part of an intentional process of coping where deliberate actions are taken. However, the ability to resist change and maintain function and identity are also coded attributes of all systems. Communities are 'resilient' and perform some sort of stability and adaptability subconsciously 'by nature', without any deliberate, intentional or planned actions taken. The resilience may lie in a structure, a state of mind, a behaviour pattern that all exist before a shock would hit the community - and such properties may even absorb a force of change without anyone noticing. Rural community resilience may, therefore, not purely be interested in crises, shocks, disturbances and other drivers of change present at a farm scale for instance (DARNHOFER, I. et al. 2010), but much more on how community functions, operates, how resilience is domesticated and embedded in everyday life.

\section{Descriptive or normative assumptions}

Secondly, when speaking about resilience, it has to be unravelled (Lendvay, M. 2013b) how we understand the concept from the aspect of normativity (BRAND, F.S. and JAX, K. 2007). In short, this means if being resilient is good at all (and for whom): if stability, persistence or the ability to transform and to adapt are the desired pathways. Also, as resilience is more than following change and implies maintaining stability, it should be clarified in what respects change should be allowed in order to secure stability in other ways. This often does not happen and more recent works - especially lay and policy discourses - seem to forget about the highly normative manner of the notion of resilience, thus, completely oversimplifying the concept. Hopkins, R. (2008) for example considers resilience itself as 'a desired state' - that is a complete misunderstanding of the basic concept. Following such abuses to the idea of resilience
Joseph, J. (2013, 51) even asserts "although we can broadly agree on what resilience is, the conclusion must be that it does not mean very much".

\section{A form of neoliberal governance}

Derived from the train of thought above, when speaking about 'rural community resilience' it emerges a question what we consider by 'rural community' and even more, what the function of the community is in making the countryside resilient. More precisely, the question is whether 'community' is a) the subject of our enquiry and serves as an unlucky synonym of rural region and is the site of certain events in say, an economic context (PiKe, A. et al. 2010), b) perhaps it is a metaphorical entity as the site that shall be preserved in a changing environment or c) whether it has some more function. Community has often been viewed as an assemblage of interacting individuals (BRIDGER, J.C. and Luloff, A.E. 1999; PANelli, R. and Welch, R. 2005) and their engagement through social networks that is the key to personal wellbeing via social support systems it offers to individuals (MAgurIE, B. and CARTwRIGHT, S. 2008). Therefore, a community itself may act as a tool for individual health and economic wellbeing so the smallest entity of 'rural community resilience' is not the group but the individual that actually takes certain actions. This implies a downward rescaling opening a discourse that "responsibilise risk away from the state and on to individuals and institutions" (WeLsh, M. 2013, 15). According to JosepH, J. the concept is genuinely suitable for neoliberal forms of governance and "despite its claims to be about the operation of systems, is, in practice, closer to a form of governance that emphasises individual responsibility" (JosepH, J. 2013, 38).

This neoliberal attitude often appears in governmental plans and community toolkits and guidelines. While the U.S. Homeland Security Council $(2007,32)$ for instance, calls for "high-level organization and efficiency 
among multiple actors". The UK Government goes even further as in its framework on community resilience it asserts its "commitment to reduce the barriers which prevent people from being able to help themselves and to become more resilient to shocks" and states that "communities (...) will have to look after themselves and each other (...). Communities will also need to work together, and with service providers, to determine how they recover" (Cabinet Office 2011, 3).

In the following sections we shall refer to these points claiming that the adaptability of a rural community is not purely the outcome of intentional actions, resilience may be about following a desired pathway as well as it may be treated as a descriptive term on remaining between threshold limits, and finally, that resilience cannot be confined to speaking about powerful community actions.

\section{Research methodology}

This study looks at how rural community resilience can be conceptualised on a casestudy focusing on the watermelon producing community of Medgyesegyháza, Békés county, Southeast Hungary. The study is built on non-representational methods (THRIFT, N. (1997) concerned with the performative 'presentations', 'showings' and 'manifestations' of everyday life (ibid, 142) as we follow CARpenter, S.R. et al. (2001) and Darnhofer, I. et al. (2016) believing that aspects of resilience may not be directly observable and measurable. In the course of data collection 25 semi-structured in-depth interviews were conducted between July and December 2013 with farmers, traders, local politicians and decision-makers and other stakeholders on community members' accounts and opinion of the processes and phenomena they experience related to farming and community life. Beyond formal interviews, numerous informal conversations were carried out in the frame of ethnographic research. This ethnographic research extended beyond the collection of textual data as methods including participant observation were also deployed in order to have a broader picture of how the community operates. This enabled us to explore those themes and issues that farmers either deliberately avoided to mention for some reason, or did not mention as they are simply not of any interest to them. Only during the process of working on the watermelon fields with day labour and loading watermelons for the traders could we understand how the fruits are treated, viewed and handled. Although the original plan was to treat the interview data and records on community life as factual, 'true' data it was found necessary to develop the research with taking into consideration Weberian substantive rationales (KALBERG, S. 1980) people follow.

\section{Aspects of community resilience in the watermelon producing community of Medgyesegyháza}

Viewed from a broader perspective, the watermelon producing community of Medgyesegyháza is located in a region classified as 'socio-economically disadvantaged'. It is characterised by a local economy based on agricultural production and the primary processing of agricultural goods coupled with low-level education and high unemployment rates that lead to a decrease in population with massive out-migration. The region is still seeking its new development pathway following the regime shift that caused the local economy to collapse - which remains highly dependent on agriculture and watermelon production since.

Although only rough estimates exist on the volume of watermelon produced and the number of people involved in farming, annual sales of watermelon seeds, Single Area Payment applications and productivity estimates give a good indication of the location and size of the industry. On a national scale, farmers have an output fluctuating around 150-200 tonnes on 4,500 ha land involved in watermelon production out of which above 2000 ha land is located in Békés county in 
the Southeastern corner of Hungary and especially converging around the nodal village of Medgyesegyháza (Figure 1). Due to the favourable natural conditions of the land and the highly intensified technology deployed in this location approximately 100-150 tonnes, more than two-thirds of the national output of watermelon is produced in the Békés region. As a consequence, whole community economies and settlement identities rely on its production.

\section{The rise of watermelon production and beyond}

Despite its current role, watermelon has not always been the primary product of the region. The local farming community has been dominantly focusing on arable paprika production before WW II, and peanut production until the 1970s before the whole community turned its interest to watermelon production. Such major transformations happened within a period of

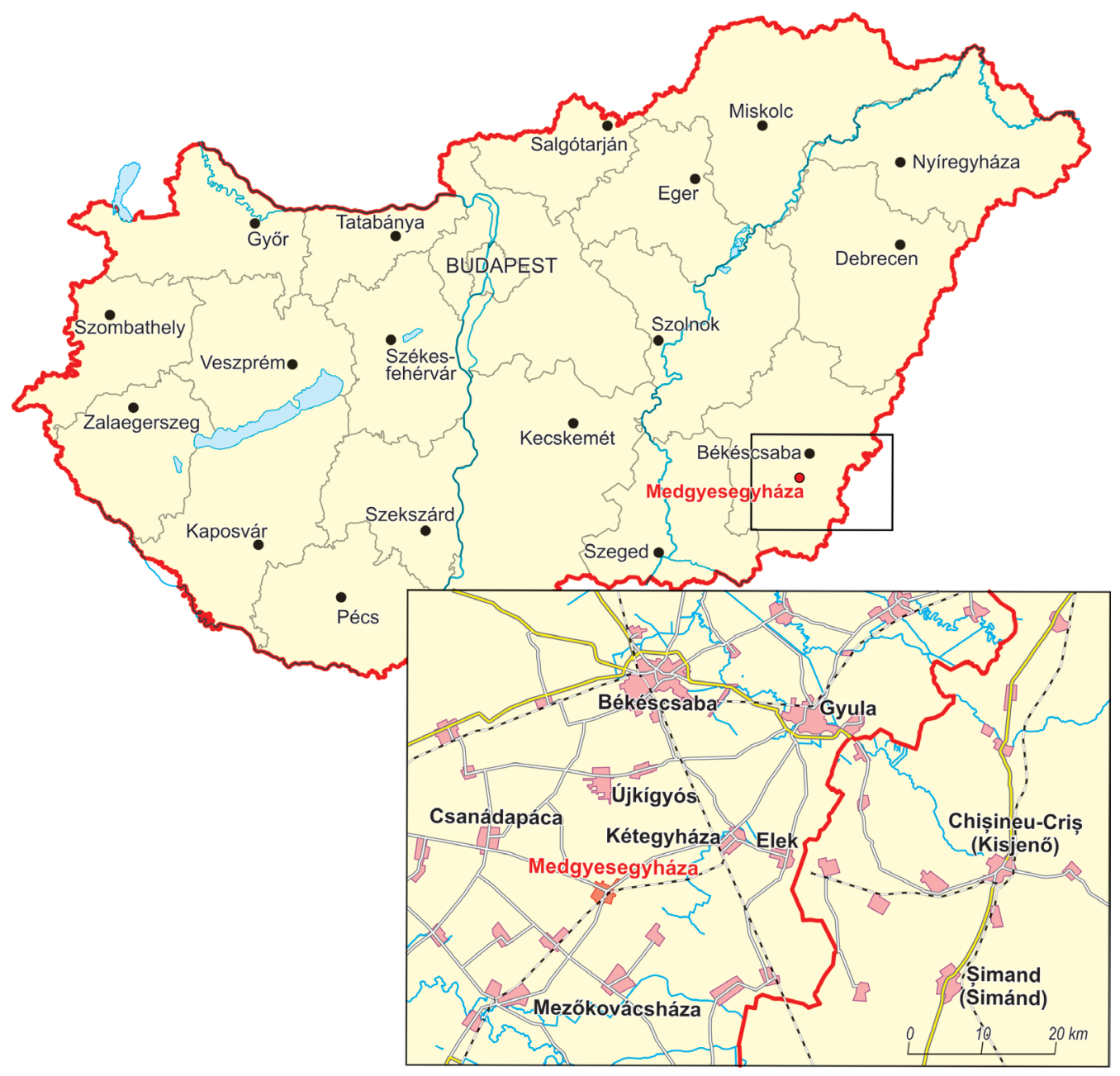

Fig. 1. The location of Medgyesegyháza and surrounding area 
only a few years' time: farmers recall the rise of watermelon production to take place between 1980 and 1983. The ground for focusing on one agricultural product was a response to collectivisation, a key component of the socialist agricultural system. Within the socialist collectives, farmers were allowed to privately cultivate only 1 ha croft lands where they tried to maximise their profit by producing crops they could sell at a high price, but that required intense care. The reason for shifting from peanut to watermelon was a response to emerging globalisation processes and pressures trickling down to a local level and became embodied by the cheap import peanuts of the Middle East and North Africa. By transforming their agricultural orientation, farmers managed to maintain their income levels, but following the changing trends had wider implications in the local community. Farmers constantly question whether they will be able to cope with external shocks and stresses.

The stress any farmer would mention as the most important factor jeopardising the community are low, and what is even more important, fluctuating market prices. As a result of moving to a neoliberal economy in the past years unpayable debt and bankruptcy of farmers many turned away from watermelon production, others even committed suicide - an event locals refer to simply as 'watermelon holocaust'. Hungary's EU accession of 2004 has also been viewed as a threat bringing in new discourses, reshaping established markets and human connections and competitors embodied especially by Greek and Italian producers who not only flood the Hungarian market but take over the export markets as well.

Interestingly, as the elderly generation still has the knowledge of peanut farming, the lands and climatic conditions remain unchanged, universal machinery are sufficient for tillage, and many households still have the peanut roasters, there are no physical barriers to the return of the peanut-age if the financial return would be more favourable. However, currently, more farmers consider extending corn production instead of returning to peanut as it is more calculable and easily mechanised.

\section{Deeply embedded practices}

In this paper, we argue that the resilience is more than the ability of a community to give responses to external forces by deliberate, planned actions. It is also a property unintentionally reproduced simply by daily practices and thus, embedded in how people treat materials and how they tie symbolic roles to them. Shocks, disturbances jeopardising the community, therefore, stem from internal processes, not only global phenomena. Watermelon production carries a number of such peculiarities that make it different from other cultures in many ways and these attributes, coupled with the habitus of community members, have a wider impact on how the community operates and is able to transform.

Firstly, current watermelon production is highly labour and technology intense and with the development of production techniques, it is becoming even more so (see Photo 1). Transplanting, grafting, the use of plastic tunnels, irrigation are all only recent developments in the farming technology. Before the regime shift farmers were short of capital to complete such investments and that these activities became in common only in the past 10-15 years. Beyond the very high financial investment demand, another implication of technological development is that it revealed the materiality of watermelons. Opposed to other arable production forms, establishing plastic tunnels, watermelon planting, hoeing and harvesting cannot be automated and is done by hand. Due to the weight and vulnerability of the fruits picking is done with a large number of seasonal labour hired by the farmers and picking follows a careful selection of ripe fruits. The physical and financial exploitation of the workers is an essential component to securing competitive prices and cheap human labour is a constant variable to the securing of the existence of the watermelon culture.

Secondly, opposed to some agricultural products (cereals, peanuts etc.) having a storage life of months, watermelon is a perishable product that has to be consumed within a few days after picking. Also, opposed 


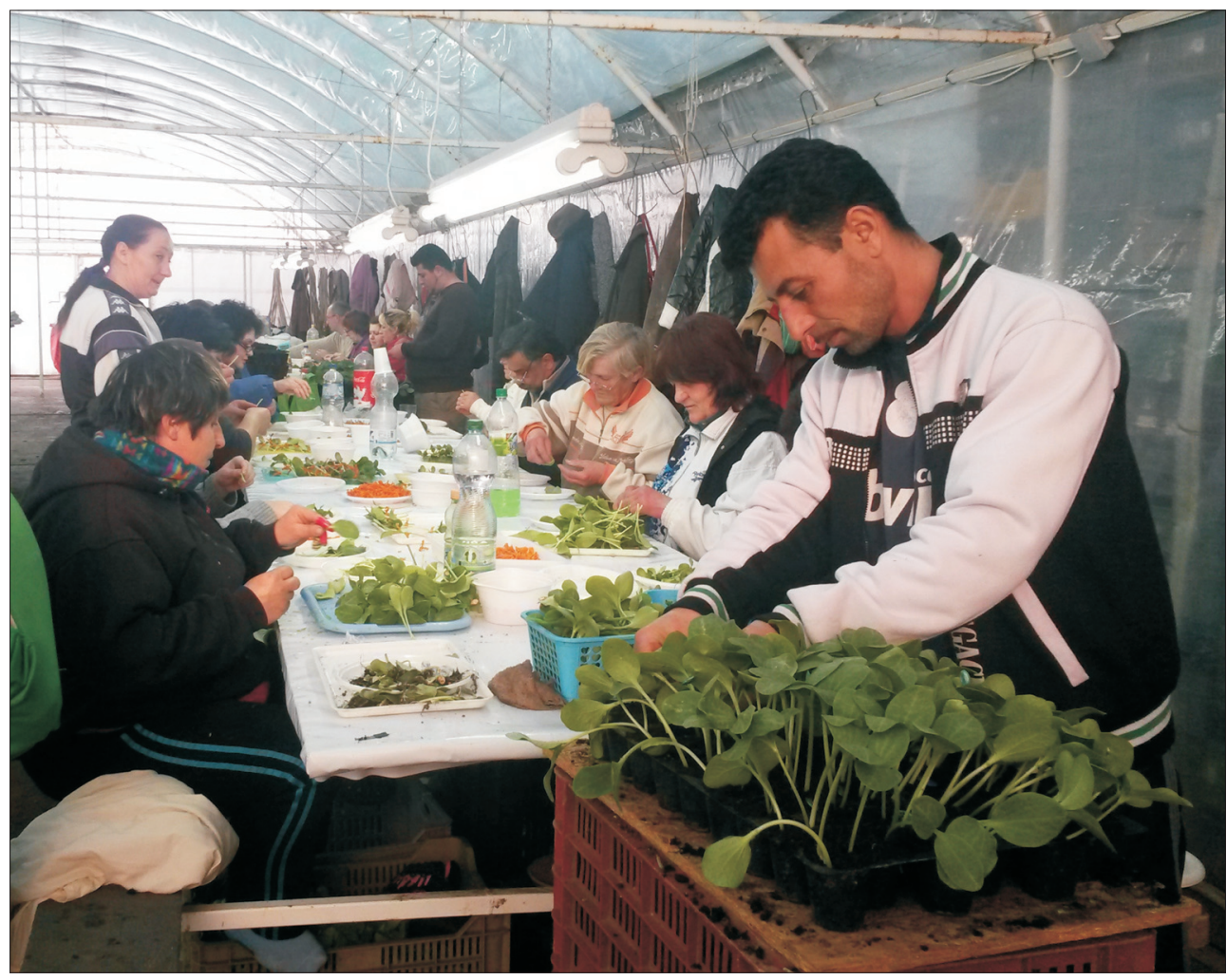

Photo 1. Watermelon grafting as a high labour intense activity. Source: Lendvay, M. 2014, private collection

to other perishable goods well-known in Medgyesegyháza (such as cucumbers, paprika) the customer demand is not steady but is extremely volatile - it highly depends on the weather at the point of possible consumption. Coded by how we consume watermelons, it has an extremely high price in the times of the season when the weather is warm, but not many fruits are ripening. This causes internally generated shocks on the low scale fast cycles of the adaptive system: farmers seek to sell unripe fruits, thus, triggering customers to turn away from Hungarian watermelon and collapsing the markets. A farmer described this situation as:

"the first watermelon fruits reach their size and weight of picking around June. But their quality is way under the standards: you know, their sugar content is low and they taste ugly, more like squash. The season has not yet started but customer demand appears in Germany with the summer, and watermelon has a high price on the market. Now this trader guy 'Menyus' appears in the neighbouring village every single year and is highly tempted to forward unripe fruits to the market. He will always find producers willing to pick and sell their products under quality but at a high price, these fruits will enter the food chain and eventually appear on the supermarket shelves! Both producer and trader make a really good deal - in the short term. Customers desperate for the refreshing fruit will buy the unripe watermelon, but only once. They will never trust our watermelon for the rest of the season. Retail dealers and foreign clients turn down future orders and our complete watermelon industry will face hardship because of a handful of producers breaching rules of the community!"

Therefore, the changing materiality of the watermelons reveals the habitus of many 
community members in terms of their low willingness to stick to community rules and their inclination towards following an opportunistic, neoliberal behaviour instead.

\section{Coping and community answers}

With all the internal and external pressures, how could then watermelon production be made more adaptive? The hardship watermelon producers suffer are reported by the media every summer (e.g. Kun, I. 2006; Szarvas, Sz. 2011) including accounts about how community members try to tackle the adverse situation. In the past years, images have often appeared in the news about farmers dumping watermelons in front of supermarkets as a protest against their pricing practices (see Photo 2). This rather naive way of attracting attention has often been criticised and experts instead pointed on the unorganised food-chain, claiming that the post-socialist legal-economic environment is still short of providing a calculable environment.
Recently, in 2013, more organised community-wide action emerged when the so-called Hungarian Melon Non-profit Association was established, an organisation that became notorious after it got engaged in a price-fixing scandal with the support of the Ministry and a number of retail chains (CsÉPAI, B. 2015). According to farmers' accounts people, in general were happy that their issues have been taken up by a pressure group, however, the intervention was not long-lived at all and had a limited reach especially as it hardly affected the low export prices. At a first glance, following the dominant discourse of what community engagement, the result of social capital and community resilience may mean this pressure group would be responsible for resilience, even though it was built on a very few local elites and lay farmers were left out of the discussions.

Searching for other forms of cooperation between farmers, the local cooperatives - or Producer Organisations - as multi-actor networks (Tregear, A. and Cooper, S. 2016), namely Medi-Fruct TÉSZ Producer

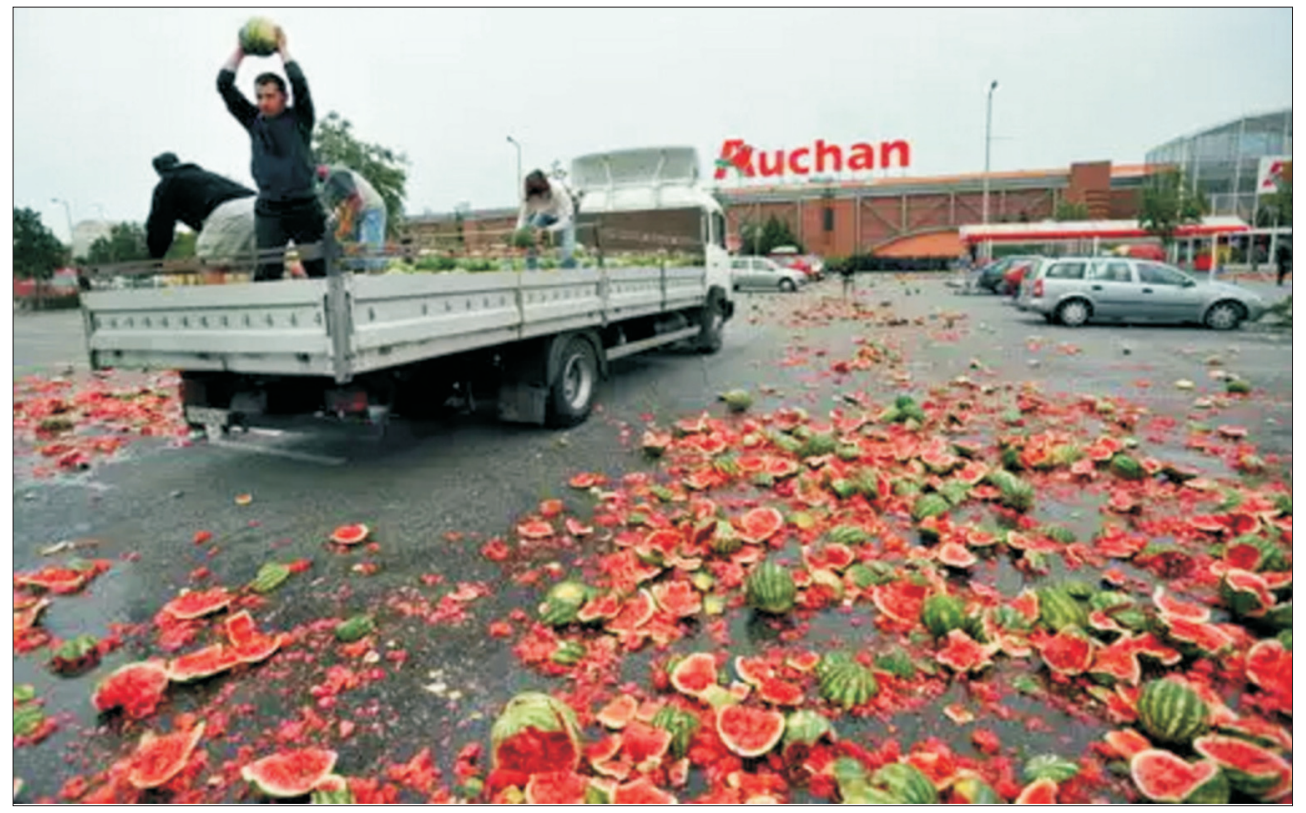

Photo 2. Watermelon producers protesting against low retail prices in 2008. Source: http://www.blikk.hu/aktualis/dinnyeozon/54zmz $9 \mathrm{w}$ 
Organisation and Magyar Termés TÉSZ Producer Organisation have to be taken into account. Interestingly, these should be the establishments that fulfil the organising, knowledge sharing roles the above-mentioned association aimed at. The POs, however are characterised by a very low level of trust between farmers and the management and so farmers seek alternative ways of cooperation instead. There is a thread of inquiry here into the post-socialist transition worth mentioning: the struggle between winners and losers of the regime shift (SwaIN, N. 2003), the bad feeling towards socialist cooperatives lead to the limited role of the formal cooperatives. Fuzzy and uncoordinated interest networks leave the community dispersed and vulnerable to low market prices.

The possible solution to tackle some of the issues comes from establishing a more strict definition of what 'quality watermelon' should be. A 'recoding' of the fruit by the amended Hungarian 82/2004 (V.11.) FVM statutory order on quality requirements watermelons should match attempted to restrict the ability of the fruit as a non-human object to modify the complete community assemblage. It is once again a change in the coded relationship between farmers, their produce and markets that determine how and when they connect.

\section{Discussion}

The question whether the rural community of Medgyesegyháza is simply 'resilient or not' is incomprehensible. Medgyesegyháza is resilient in so far as watermelon production has been the flagship product of the municipality for the past 30 years; farmers have been constantly learning and developing their technology and were able to implement unorthodox measures when it came to securing farm gate prices. However, both the number of local population and farmers engaged in watermelon production is decreasing and the community may easily loose its identity if they drop watermelon farming for other cultures - the question is where the thresh- old limits are. Here resilience is much more embedded in structures of daily life than the planned agency of community actors.

We argue here that resilience in this sense is an extremely ambiguous term. Viewing community change from a wider perspective, we may ask what happened at all if the watermelon industry collapsed and the farming community of Medgyesegyháza ceased to thrive on watermelon farming. Would that be a sign of resilience? It should be visible by now, that resilience is more than the response of a single entity to an individual shock, but the interplay of overt actions and processes and deeply embedded structures. We may determine what properties of the rural community shall remain constant (e.g. the income level of the farmers, the identity of a unique farming culture) and treat resilience thinking as a normative tool of governance to reach this single goal. Resilience, however, will always remain a value-free way of thinking about change and cross-scale relationships.

Despite all the risks surrounding the concept of resilience, there are potential avenues where the concept could be harnessed to better understand the changing post-socialist environment. In any of the following cases, a holistic approach must be applied unfolding the interconnectedness of components of the rural environment and the impacts of certain events on different scales.

Firstly, by applying a historical perspective we may seek to answer questions about how the ongoing post-socialist transition from planned economy to a neoliberal system tousled existing structures, built new ties between people, institutions, markets, discourses etc. and how these filter down and become a lived experience. It is important to understand in what ways agricultural communities may have gained new possibilities and became vulnerable to previously unseen globalisation processes at the same time. Of especial interest here is the EU accession of many post-socialist states that may have offered the reach of new markets, but that required more discipline and vigilance from farmers. New relationships were established 
between farmers and markets that clashed with the traditional habits. These new, hybrid forms of capitalist, neoliberal and the remaining socialist attitudes created a unique economic and social environment.

Secondly, the post-socialist environment has been characterised by 'low' social capital where the low level of general trust, the high role of kinship, the opportunist behaviour of actors or an excessive role of elites may restrain the adaptability of the community and may make it vulnerable to shocks. In practical terms, this arrangement of social capital reveals itself in the all-pervading impact of local politicians, the high socio-economic influence of those persons already in some sort of power before the regime shift. Also, due to the memories of the socialist cooperative, there is a low willingness to take part in formal cooperation. By building on the concept of social capital, we may investigate the structures of human and institutional relationships and networks, explore the forms of community engagement and cooperation, and unfold which actors the drivers of the existing community-wide actions actually are. Critically analysing social relations and structures of the community leads us to understand how people are able to determine their own futures via cooperation, and to what extent they are vulnerable to - or even, are the source of - economic shocks.

Thirdly, extending our inquiry to non-human components such as materials, technologies, discourses, we may investigate how such components, their physicality and the meanings people attach to them exert power in both stabilising and reshaping the community with special regards to the impact they may have on human relations. In particular, a potential pathway for such investigations is to tie together broader properties of the post-socialist space and the changing materiality of objects, such as the agricultural products. Farmers of Eastern Europe have traditionally suffered from the lack of capital which prevented them from introducing new technologies and products. Grafting, for example, a very investment demanding technique could only appear ten years ago, but the spread of the use of expen- sive, quality seeds is also a new achievement that results in more expensive produce and changing relationships between farmers, seasonal labour and agricultural products.

Fourthly, a resilience approach may help us understand the 'limits' of communities, and define those points in space and time where and when they irreversibly lose some functions or develop others. This inquiry may look beyond the financial reasons (such as changing subsidiary payments) and consequences of functional changes and investigate what impact this may have on culture and identity. Processes characteristic to post-socialist states such as mass out-migration and subsequent hardships within the labour market, the loss of local knowledge, but also changing environmental conditions such as climate change and the following demand for irrigation may all lead to shifts in agricultural cultures and irreversible loss of community identity. It is a question, however, where the tipping points for these events take place and defining the threshold limits is also a resource for wellgrounded policy interventions.

No matter which one of these approaches we follow in our research, we have to keep in mind a number of general rules. There is a high risk of conducting comparative studies, as selecting the right case-studies and the set of common denominators for analysis may narrow the scope of the study. Also, not taking into consideration the very local factors during comparing, the whole concept may easily become simplified and the required holistic approach may collapse. Similarly, research on 'strengthening' resilience is a very risky task. Such an undertaking will also implicitly have to focus on a limited number of variables and selected processes. We highly recommend to clearly define 'resilience of what to what' CARPENTER, S.R. et al. (2001) shall be strengthened, also to assert what identity, form of functioning, economic output level, population number etc. is meant to be preserved and 'what lines of flight' (Deleuze, G. and GuATTARI, F. (1987), forms of transformation we consider as acceptable when speaking about resilience itself as a policy goal. 


\section{Conclusions}

Resilience thinking in geography has become extremely popular in the past decade in the Anglo-Saxon literature. Its popularity in academic, policy and lay discourses quickly resulted in resilience becoming a catchword with a limited meaning as it carried two conflicting meanings at the same time: resilience either meant an ability to change or an ability to remain in a stable condition. At the same time, having its origins in ecology and psychology, traditional applications focus either on broader structures or actions of individuals, and so the existing literature is characterised by a structure-agency dichotomy. Resilience has also become imbued with neoliberal values as works on community resilience often used the term in a normative way assuming intentionality, what also made it a tool of neoliberal governance.

However, resilience means much more than a respond to a shock, or the adaptability of a community to cope with adversity. In its original meaning, it is the interplay of process embedded in daily actions involving humans, institutions, non-human objects but also beliefs and discourses that mark the directions of possible transformation and stabilise the community assemblage at the same time. When used as an analytical tool, resilience is a concept that helps us understand the dynamics of such adaptability and persistence, and unfolds why and how regions and communities change or manage to maintain functioning and sustain their identity.

At the same time, resilience has not been used in a post-socialist context so far. We argue here that the characteristics of the post-socialist environment make it an ideal field for applying resilience thinking, and vice versa, the post-socialist transition and the processes within post-socialist states can be better understood by applying resilience thinking. We find possible uses of the concept in a rural post-socialist context to focus on how large-scale economic and political processes of post-socialist transition trickle down and become lived experiences, to ana- lyse the impacts of community engagement and cooperation, to investigate the role of changing non-human components, and to examine where the points of irreversible community transformation are in post-socialist transition. Resilience thinking has a significant potential in research in the fields of geography in post-socialist states and we expect the spread of works on resilience in the forthcoming years following the introduction of the concept to the post-socialist research environment.

Acknowledgements: The author thanks Professor Michael Woods and Dr Jesse Heley for helpful discussions and the referees for the incisive comments. The Doctoral Career Development Scholarship by Aberystwyth University is gratefully acknowledged.

\section{REFERENCES}

Adey, P. and Anderson, B. 2011. Event and anticipation: UK Civil Contingencies and the space - times of decision. Environment and Planning $A$ 43. 2878-2899.

Adger, W.N. 2000. Social and Ecological Resilience: Are They Related? Progress in Human Geography 24. (3): 347-364.

Almedom, A. 2005. Social capital and mental health: An interdisciplinary review of primary evidence. Social Science and Medicine 61. 943-964.

Amundsen, H. 2012. Illusions of resilience? An analysis of community responses to change in Northern Norway. Ecology and Society 17. (4): 14

Berkes, F. and Ross, H. 2013. Community Resilience: Toward an Integrated Approach. Society E Natural Resources: An International Journal 26. (1): 5-20.

BRAND, F.S. and JAX, K. 2007. Focusing the meaning(s) of resilience: resilience as a descriptive concept and a boundary object. Ecology and Society 12. (1): 23.

Bridger, J.C. and Luloff, A.E. 1999. Toward an interactional approach to sustainable community development. Journal of Rural Studies 15. 377-387.

Brown, D. and Kulig, J. 1996/97. The concept of resiliency: Theoretical lessons from community research. Health and Canadian Society 4. 29-50.

Buikstra, E., Ross, H., King, C.A., BaKer, P.G., Hegney, D., Mclachlan, K. and Rogers-Clark, C. 2010 The components of resilience: perceptions of an Australian rural community. Journal of Community Psychology 38. 975-991.

Cabinet Office 2011. Strategic National Framework on Community Resilience. London, Cabinet Office, 28. 
Carpenter, S.R., Walker, B.H., Anderies, J.M. and Abel, N. 2001. From metaphor to measurement: Resilience of what to what? Ecosystems 4. 765-781.

Cheshire, L., Esparcia, J., Shucksmith, M. 2015. Community resilience, social capital and territorial governance. Journal of Depopulation and Rural Development Studies 18. 7-38.

Csépai, B. 2015. The ceasefire is over. European Competition Law Review 36. (9): 404-405.

Darnhofer, I., Fairweather, J. and Moller, H. 2010. Assessing a farm's sustainability: insights from resilience thinking. International Journal of Agricultural Sustainability 8. (3): 186-198.

Darnhofer, I., Lamine, C., Strauss, A. and Navarrete, M. 2016. The resilience of family farms: Towards a relational approach. Journal of Rural Studies 44 . 111-122.

DeLanda, M. 2002. Intensive Science and Virtual Philosophy. London, Continuum, 248.

DeLanda, M. 2006. A New Philosophy of Society: Assemblage Theory and Social Complexity. London, Continuum, 148.

Deleuze, G. and Guattari, F. 1988. A thousand plateaus: capitalism and schizophrenia. Minneapolis, University of Minnesota Press, 610.

Dwiartama, A. and Rosin, C. 2014. Exploring agency beyond humans: the compatibility of ActorNetwork Theory (ANT) and resilience thinking. Ecology and Society 19. (3): 28.

Exterckoter, R.K., DA Silva, C.A., Tulla Pujol, A.F. 2015. Family farmers as agents of resilience in the western region of Santa Catarina (Brazil). Journal of Depopulation and Rural Development Studies 18. 115-138.

Flora, C., Flora, J. and Fey, S. 2004. Rural communities: Legacy and change. Boulder, Westview Press, 372.

Garmezy, N. 1973. Competence and adaptation in adult schizophrenic patients and children at risk. In Schizophrenia: The first ten Dean Award lectures. Ed.: DeAN, S.R. New York, MSS Information, 163-204.

Gunderson, L.H. and Holling, C.S. 2002. Panarchy: understanding transformations in human and natural systems. Washington D. C., Island Press, 448.

Holling, C.S. 1973. Resilience and Stability of Ecological Systems. Annual Review of Ecology and Systematics 4. 1-23.

Homeland Security Council 2007. National Strategy for Homeland Security. Washington D. C., Homeland Security Council, 53.

Hopkins, R. 2008. The Transition Handbook: From Oil Dependency to Local Resilience. Totnes, Green Books, 240.

Hudson, R. 2010. Resilient regions in an uncertain world: wishful thinking or a practical reality? Cambridge Journal of Regions, Economy and Society 3. 11-25.

JosePh, J. 2013. Resilience as embedded neoliberalism: a governmentality approach. Resilience 1. (1): 38-52.
Kalberg, S. 1980. Max Weber's Types of Rationality: Cornerstones for the Analysis of Rationalization Processes in History. The American Journal of Sociology 85. (5): 1145-1179.

KAPLAN, H.B. 1999. Toward an understanding of resilience: A critical review of definitions and models. In Resilience and development: Positive life adaptations. Eds.: Glantz, M.D. and Johnson, J.L., New York, Kluwer Academic/Plenum, 17-84.

Kun, I. 2006. Vélemény (Opinion). HVG, http://hvg. hu/velemeny/200622HVGFriss146 Accessed on 08.10. 2015.

LATour, B. 2005. Reassembling the Social: An Introduction to ActorNetworkTheory. Oxford, Oxford University Press, 312.

Lendvay, M. 2013a. Rethinking rural community resilience. Conference presentation. $25^{\text {th }}$ Congress of the European Society for Rural Sociology, 29 July-1 August 2013, Florence, Italy. E-proceedings of the $25^{\text {th }}$ congress of the European Society for Rural Sociology (ESRS) 121.

Lendvay, M. 2013b. Debates in resilience: Capturing the role of intangible infrastructures. In Strengthening Intangible Infrastructures. Eds.: KAPfERER, E., KocH, A. and Sedmak, C., Newcastle, Cambridge Scholars Publishing, 161-176.

Ludwig, D., Walker, B. and Holling, C.S. 1997. Sustainability, stability, and resilience. Conservation Ecology 1. (1): 7.

Magis, K. 2010. Community resilience: an indicator of social sustainability. Society and Natural Resources 23. 401-416.

Magurie, B. and Cartwright, S. 2008. Assessing a community's capacity to manage change: A resilience approach to a social assessment. Canberra, Australian Government Bureau of Rural Sciences, 33.

Marsden, T.K. 2003. The condition of rural sustainability. Assen, Royal van Gorcum, 267.

Norris, F.H., Stevens, S.P., Pfefferbaum, B., Wyche, K.F. and Pfefferbaum, R.L. 2008. Community Resilience as a Metaphor, Theory, Set of Capacities, and Strategy for Disaster Readiness. American Journal of Community Psychology 41. (1-2): 127-150.

Panelli, R. and Welch, R. 2005. Why community? Reading difference and singularity with community. Environment and Planning A 37. 1589-1611.

Pike, A., Dawley, S. and Tomaney, J. 2010. Resilience, adaptation and adaptability. Cambridge Journal of Regions, Economy and Society 3. 59-70.

Ross, H., Cuthill, M., Macklean, K., Jansen, D. and WITT, B. 2010. Understanding, enhancing and managing for social resilience at the regional scale: opportunities in North Queensland. Report to the Marine and Tropical Sciences Research Facility. Cairns, Reef and Rainforest Research Centre Limited, 188.

Scotт, M. 2013. Resilience: a Conceptual Lens for Rural Studies? Geography Compass 7. (9): 597-610. 
Smith, E. and Marsden, T.K. 2004. Exploring the 'limits to growth' in UK organics: beyond the statistical image. Journal of Rural Studies 20. (3): 345-357.

StiRLing, A. 2014. From Sustainability, through Diversity to Transformation: Towards More Reflexive Governance of Vulnerability. In Vulnerability in Technological Cultures: New Directions in Research and Governance. Eds.: Hommels, A., Mesman, J. and Bijker, W., Cambridge, MIT Press, 305-332.

SwaIn, N. 2003. Social Capital and its Uses. European Journal of Sociology 44. 185-212.

Szarvas, Sz. 2011. Az összefogás megmentheti a magyar dinnyepiacot. (Co-operation can save the water melon market in Hungary). http://gazdakor.agro.hu/index.php?id= 90\&tx_ttnews\%5Btt_news\%5D=793. Accessed on 02.03.2016.
Thrift, N. 1997. The still point: resistance, expressive embodiment and dance. In Geographies of Resistance. Eds.: Pile, S. and Keith, M., London, Routledge, 124-151.

Tregear, A. and Cooper, S. 2016. Embeddedness, social capital and learning in rural areas: The case of producer cooperatives. Journal of Rural Studies 44. 101-110.

WALKer, B. 2012. A commentary on "Resilience and water governance: adaptive governance in the Columbia River Basin". Ecology and Society 17. (4): 29.

WELSH, M. 2013. Resilience and responsibility: governing uncertainty in a complex world. Geographical Journal 180. 15-26. 